\title{
Promotive effects of cell proliferation and chromosomal instability induced by tribbles-related protein 3 in mouse mammary tumor cells
}

\author{
YUTO SAKAI $^{1,2}$, KATSUMI FUKAMACHI ${ }^{1}$, MITSURU FUTAKUCHI $^{1}$, \\ HIDETOSHI HAYASHI ${ }^{2}$ and MASUMI SUZUI ${ }^{1}$
}

\begin{abstract}
${ }^{1}$ Department of Molecular Toxicology, Nagoya City University Graduate School of Medical Sciences and Medical School, 1 Kawasumi, Mizuho-cho, Mizuho-ku, Nagoya 467-8601; ${ }^{2}$ Department of Drug Metabolism and Disposition, Nagoya City University Graduate School of Pharmaceutical Sciences, 3-1 Tanabe-dori, Mizuho-ku, Nagoya 467-8603, Japan
\end{abstract}

Received January 23, 2013; Accepted March 28, 2013

DOI: 10.3892/or.2013.2441

\begin{abstract}
Tribbles-related protein 3 (TRB3) has been shown to be a crucial modulator of tumorigenesis. However, the precise role and the functional morphology of TRB3 are not clearly understood. To elucidate these enigmas we established the cell line, M2TRB3, by introducing the human TRB3 gene and protein in Cl66M2 (M2) mouse mammary tumor cells. This cell line stably expressed the TRB3 gene and protein. After $72 \mathrm{~h}$ of cell culture, there was a $34 \%$ increase in the growth of M2TRB3 cells compared to the control M2 mock cells. The mean volume of the tumors originating from the M2TRB3 cells was significantly increased by $38 \%$ when compared to the mean volume of the M2 mock tumors, and the proliferating cell nuclear antigen (PCNA) labeling index in the M2TRB3 tumors was higher when compared to that of the M2 and M2 mock cells. In the tumor tissue samples, the mean diameter of nuclei in the M2TRB3 tumor cells $(9.4 \pm 0.3 \mu \mathrm{m})$ showed a significant increase compared to that of the M2 mock tumor cells (7.0 $\pm 0.2 \mu \mathrm{m})$. M2TRB3 cells also showed a marked increase in the population of tetraploid or octaploid nuclei compared to M2 mock cells bearing mainly either diploid or tetraploid nuclei. Western blot analysis revealed the overexpression of cyclin B1 and cyclin D1 in M2TRB3 cells when compared to that in the M2 mock cells. These novel findings provide further evidence that TRB3 promotes cell proliferation and chromosomal instability by causing polyploidization during development.
\end{abstract}

Correspondence to: Dr Masumi Suzui, Department of Molecular Toxicology, Nagoya City University Graduate School of Medical Sciences and Medical School, 1 Kawasumi, Mizuho-cho, Mizuho-ku, Nagoya 467-8601, Japan

E-mail:suzui@med.nagoya-cu.ac.jp

Key words: tribbles-related protein 3, cell proliferation, ploidy, tumor xenograft

\section{Introduction}

Tribbles-related protein 3 (TRB3, also known as NIPK, SKIP3) is a mammalian homologue of the Drosophila Tribbles gene, and this gene has been identified as an inhibitor of mitosis that regulates cell proliferation, migration and morphogenesis during development (1-3). Among tribbles homologues TRB1, TRB2 and TRB3, TRB3 is the most recently defined family of pseudokinases that contain a serine/threonine kinase catalytic domain but lack an ATP binding site or one of the conserved catalytic motifs essential for kinase activity (4). The interacting partners of TRB3 range from transcription factors, ubiquitin ligase, bone morphogenetic protein (BMP) type II receptor to members of the mitogen-activated protein kinase (MAPK) and phosphoinositide 3-kinase (PI3K) signaling pathways. By interacting with these proteins, it coordinates crucial cellular processes, including glucose/lipid metabolism, apoptosis, adipocyte differentiation, cell stress and regulation of collagen expression (5-9). We previously demonstrated that TRB3 is induced by $\mathrm{C} / \mathrm{EBP}$ homologous protein (CHOP) and activating transcription factor 4 (ATF4) to regulate their function and endoplasmic reticulum (ER) stress-induced cell death (10) and that TRB3 also regulates the stability of cell division cycle 25A (Cdc25A), an essential activator of cyclindependent kinases (CDKs) (11).

Recent studies indicate that the three mammalian tribbles homologues are crucial modulators of tumorigenesis. For instance, both TRB1 and TRB2 are involved in myeloid leukemogenesis $(12,13)$. TRB3 is highly expressed in a wide range of human carcinoma cell lines and in several types of human carcinomas $(4,14)$. However, a precise role of TRB3 in tumorigenesis remains unknown. The aim of the present study was to examine whether the introduction of the human TRB3 gene into mouse mammary tumor cells affects in vitro/in vivo growth and chromosomal stability during cell division of tumor cells.

\section{Materials and methods}

Cell culture. The human embryonic kidney cell line 293 purchased from the American Type Culture Collection (ATCC, 
Manassas, VA, USA) and the human hepatocellular carcinoma cell line HepG2 were cultured in Dulbecco's modified Eagle's medium(DMEM; Wako Pure Chemical Industries, Ltd., Osaka, Japan) supplemented with $10 \%$ fetal bovine serum (FBS; Life Technologies, Inc., Rockville, MD, USA) in a humidified incubator with $5 \% \mathrm{CO}_{2}$ at $37^{\circ} \mathrm{C}$. The murine mammary tumor cell line Cl66M2 (M2) was generously provided by Dr Rakesh K. Singh (University of Nebraska Medical Center, Omaha, NE, USA) (18) and cultured in DMEM supplemented with 5\% FBS in a humidified incubator with $5 \% \mathrm{CO}_{2}$ at $37^{\circ} \mathrm{C}$.

Construction of the expression vector. The TRB3 flag-tagged expression vector was constructed by ligating the full length human TRB3 cDNA into BamHI and XhoI restriction sites of pcDNA3.1-Hygro (Life Technologies, Inc.) (9). The construct was verified by sequencing.

Preparation of a cell line that stably expresses the TRB3 gene. The expression vector pcDNA3.1-Hygro-flag-human TRB3 was transfected into Cl66M2 cells using Lipofectamine 2000 reagent (Life Technologies, Inc.). This cell line was termed M2TRB3. After transfection, the clone of the cells stably expressing M2TRB3 was selected by a limiting-dilution method in culture media supplemented with hygromycin. The cells transfected with the empty vector were also prepared as the control (M2mock). In M2TRB3 and M2mock cells, the levels of mRNA and protein expression were confirmed by reverse transcription-polymerase chain reaction (RT-PCR) and western blot assays.

In vitro cell proliferation assay. These assays were performed as described previously by us (15). Two murine mammary tumor cell lines M2TRB3 and M2mock were plated into 6-well $35-\mathrm{mm}$ diameter culture plates $\left(1.0 \times 10^{4}\right.$ cells/well) in DMEM containing $10 \%$ FBS. Cells were starved in DMEM containing $0.5 \% \mathrm{FBS}$ for $48 \mathrm{~h}$. After starvation, the culture media were removed and cells were grown in DMEM containing 10\% FBS for the indicated time course $(0-72 \mathrm{~h})$. The cells were washed twice with phosphate-buffered saline (PBS), harvested, resuspended in $1 \mathrm{ml}$ PBS and the number of cells was determined using a hemocytometer Burker-Turk (Erma Inc., Tokyo, Japan). Each assay was repeated more than three times to confirm the results. The number of cells was plotted on a time-response curve as indicated in the figures.

Tumor xenograft assay. Male four-week-old BALB/cSlc-nu/nu mice obtained from Japan SLC, Inc. (Shizuoka Japan) were used. M2, M2TRB3 and M2mock cells $\left(1.0 \times 10^{6} / 200 \mu 1\right)$ were subcutaneously inoculated into the right lower flank of the mice. Tumor diameters $(\mathrm{mm})$ and body weight $(\mathrm{g})$ were recorded twice weekly. The tumor volume $\left(\mathrm{mm}^{3}\right)$ was calculated by the formula: Volume $=\mathrm{L} \times \mathrm{D} \times \mathrm{H} \times \pi / 6$, where $\mathrm{L}$ is the length, $\mathrm{D}$ is the depth, and $\mathrm{H}$ is the height. At 35 days after inoculation, all mice were euthanized and complete autopsies were performed. Animal experiments were conducted in accordance to the regulations specified by the Institutional Animal Use and Care Committee of Nagoya City University.

Immunohistochemistry and measurement of proliferating cell nuclear antigen (PCNA) labeling index. These assays were performed using an established method as described previously by us (16). Paraffin sections $(3-\mu \mathrm{m})$ were prepared to include tumors resected from the lower flank of each mouse. These sections were treated in $3 \% \mathrm{H}_{2} \mathrm{O}_{2}$ for 10 min to block the endogenous peroxidase activity. For antigen retrieval, the sections were brought to boiling in $0.1 \mathrm{M}$ citrate buffer, $\mathrm{pH}$ 6.0. Sections were incubated with a primary antibody of PCNA (1:500 dilution) (sc-56; Santa Cruz Biotechnology, Inc., Santa Cruz, CA, USA) at room temperature for $60 \mathrm{~min}$. After incubation with the secondary antibody, sections were then stained using an ABC kit (Vector Laboratories, Inc., Burlingame, CA, USA) according to the manufacturer's instructions. The PCNA labeling index was determined by calculating the ratio of PCNA-positive nuclei/total number of nuclei counted. Ten high power fields $(x 400)$ per tumor were examined, and $>300$ cells were counted in each tumor. In M2TRB3 and M2mock tumors, the longest diameter of the nucleus was determined by image analysis using Olympus DP70 system (Olympus Corp., Tokyo, Japan). Four high power fields (x400) per tumor were examined and more than 100 nuclei were counted in each tumor.

Flow cytometric analysis. These assays were performed as previously described (16). M2TRB3 and M2mock cells $\left(7.5 \times 10^{4}\right.$ cells/plate) were plated onto $9-\mathrm{cm}$ culture dishes in DMEM plus $10 \%$ FBS and grown to yield 50-60\% confluence. To synchronize cells at the G0/G1 phase, they were starved by culturing in DMEM plus $0.5 \%$ FBS for $48 \mathrm{~h}$. After starvation, cells were then growth in DMEM plus $10 \%$ FBS for $72 \mathrm{~h}$. Adherent cells were washed twice with PBS, fixed with $5 \mathrm{ml} 70 \%$ ethanol, centrifuged, resuspended in $400 \mu 1$ PBS containing $2 \mathrm{mg} / \mathrm{ml}$ RNase (Nacalai Tesque, Inc., Kyoto, Japan), and stained with $400 \mu \mathrm{l}$ of $0.1 \mathrm{mg} / \mathrm{ml}$ propidium iodide (Sigma-Aldrich, St. Louis, MO, USA) in the dark for $30 \mathrm{~min}$ or overnight. The cell suspension was filtered through a $60-\mu \mathrm{m}$ nylon filter (Ikemoto Scientific Technology Co., Ltd., Tokyo). Samples of 10,000-20,000 cells were then analyzed for cell cycle phase distribution and ploidy status using a FACSCalibur ${ }^{\mathrm{TM}}$ instrument, and the data were analyzed with the CellQuest computer program (both from Becton-Dickinson, Franklin lakes, NJ, USA) as described in a previous study (16). Cells were harvested just after starvation $(0 \mathrm{~h})$ and $72 \mathrm{~h}$ after starvation as described in Table I and Fig. 5. Each assay was repeated more than three times to confirm the results.

RT-PCR assays. These assays were conducted using previously established procedures (16). Total RNA was extracted from each cell line grown in 9-cm culture dishes using Isogen (Nippon Gene, Toyama, Japan). The reaction mixture contained $4 \mu \mathrm{g}$ of total RNA, $1 \mu \mathrm{l}$ of $10 \mathrm{mM} \mathrm{dNTP}, 1 \mu \mathrm{l}$ of random primers (both from Life Technologies, Inc.) and $7 \mu 1$ of distilled water. The reaction mixture was incubated at $65^{\circ} \mathrm{C}(5 \mathrm{~min})$ for denaturation, chilled on ice for $1 \mathrm{~min}$ and $4 \mu \mathrm{l}$ of $5 \mathrm{X}$ RT buffer (Life Technologies, Inc.), $1 \mu \mathrm{l}$ of $0.1 \mathrm{M}$ dithiothreitol (DTT), $1 \mu \mathrm{l}$ of the RNaseOut and $1 \mu \mathrm{l}$ of Superscript ${ }^{\circledR}$ III Reverse Transcriptase (both from Life Technologies, Inc.) were added. After the addition of these reagents, the reaction mixture was incubated at $50^{\circ} \mathrm{C}(60 \mathrm{~min})$ for random primer annealing and $70^{\circ} \mathrm{C}(15 \mathrm{~min})$ for cDNA preparation. One microliter of the reaction mixture was then used for PCR. The primer sequences used in this study were as follows: human TRB3-specific 

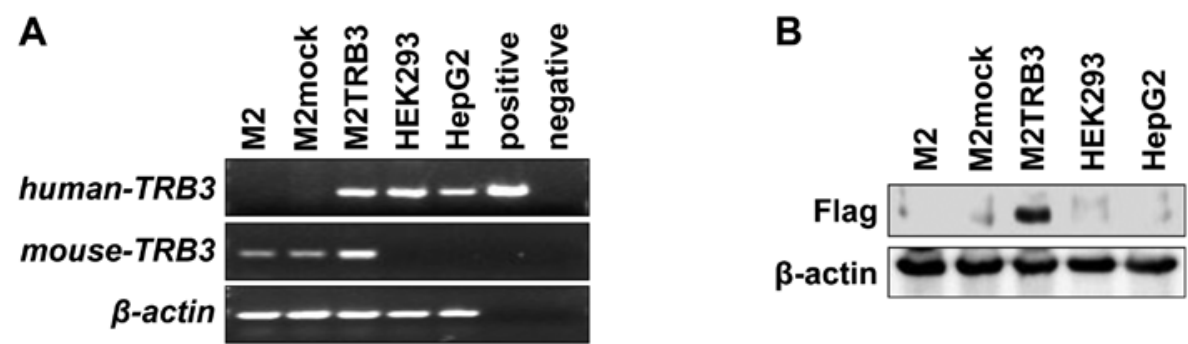

Figure 1. Expression status of exogenous human TRB3 and endogenous mouse TRB3 in the indicated cell lines. (A) Representative results of the RT-PCR analysis. The band in the positive control was derived from DNA fragments that were PCR-amplified using pcDNA3.1-Hygro-flag-human TRB3 vector as a template and the pairs of gene-specific primers listed in Materials and methods. No band was noted in the negative control since the empty vector (pcDNA3.1Hygro) that does not carry specific sites for the primers was used as a template for PCR. Bands of $\beta$-actin were not observed in the positive and negative control samples due to the same reason as the negative control. (B) Representative results of the western blot analysis. The exogenous human TRB3 (Flag) protein was detected in the M2TRB3 cells.

primer set, hTRB3F (5'-CAAGTCGCTCTGAAGGTTCC-3') and hTRB3R (5'-CCATCCTACTCTGGCAAAGC-3'), mouse TRB3-specific primer set, mTRB3F (5'-CAAGTCGCTCT GAAGGTTCC-3') and mTRB3R (5'-CCATCCTACTC TGGCAAAGC-3'), respectively.

$\beta$-actin-specific DNA fragments from the same RNA samples were amplified and served as internal controls. Primers actinF (5'-CCGTAAAGACCTCTATGCCAACA-3') and actinR (5'-CGGACTCATCGTACTCCTGCTT-3') were used for amplification of $\beta$-actin. PCR was conducted for 26-30 cycles in an iCycler (Bio-Rad Laboratories, Inc., Hercules, CA, USA). Each amplification cycle consisted of $0.5 \mathrm{~min}$ at $94^{\circ} \mathrm{C}$ for denaturation, $0.5 \mathrm{~min}$ at $60^{\circ} \mathrm{C}$ for primer annealing, and $1 \mathrm{~min}$ at $72^{\circ} \mathrm{C}$ for extension. After PCR amplification, the DNA fragments were stained with ethidium bromide and analyzed by $2 \%$ agarose gel electrophoresis. The results were confirmed by repeating the experiments.

Western blot assays. These assays were conducted according to previously established procedures (17). The cells were lysed in radioimmunoprecipitation assay (RIPA) buffer [50 $\mathrm{mM}$ Tris- $\mathrm{HCl}(\mathrm{pH} 8.0), 150 \mathrm{mM} \mathrm{NaCl}, 0.1 \%$ sodium dodecyl sulfate (SDS), $0.5 \%$ deoxycholate, and $1 \%$ Triton X-100]. The lysates were subjected to SDS-polyacrylamide gel electrophoresis (PAGE) (12.5\%), transferred onto a polyvinylidene difluoride (PVDF) membrane (Immobilon P; Millipore Corp., Bedford, MA, USA) and probed with the antibodies. The primary antibodies used in the present study were anti- $\beta$-actin monoclonal antibody (AC-15) (Sigma-Aldrich), anti-cyclin B1 monoclonal antibody (sc-245) (Santa Cruz Biotechnology Inc.), anti-Cdc2 monoclonal antibody (sc-54), anti-Cdk2 polyclonal antibody (sc-163), anti-Cdk4 polyclonal antibody (sc-260), anti-TRB3 polyclonal antibody (sc-34211), anti-cyclin D1 monoclonal antibody (556470; Becton-Dickinson), and anti-Flag monoclonal antibody (018-22381) (Wako Pure Chemical Industries, Ltd.). The immunoreactive proteins were visualized using ImmunoStar Zeta (Wako Pure Chemical Industries, Ltd.) and light emission was quantified with Light Capture (ATTO Corp., Tokyo, Japan). Each assay was repeated more than three times to confirm the results.

Statistical analysis. Differences in the number of cells, tumor volume, PCNA labeling index, and rate of DNA ploidy between cell lines or tumor origins were analyzed by the Student's or
Welch's t-test. A value of $\mathrm{P}<0.05$ was considered to indicate a statistically significant result.

\section{Results}

TRB3 expression in the M2TRB3 cells. To examine the role of TRB3 in cell proliferation, we developed a cell line (M2TRB3) that stably expresses the human TRB3 gene by transfecting the gene into murine mammary tumor cell line Cl66M2 (M2) (18). We also developed the control cells (M2mock) transfected with empty vector pcDNA3.1-Hygro. M2TRB3 cells expressed both human TRB3 mRNA and mouse TRB3 mRNA (Fig. 1A). Human embryonic kidney cell line HEK293 and human hepatoma cell line HepG2 also expressed human TRB3 mRNA. There was no mRNA expression of human TRB3 in the M2 and M2mock cells. Human TRB3 DNA was PCR-amplified from pcDNA3.1-Hygro-flag-human TRB3 vector and the band was present in the positive lane in Fig. 1A. Expression of the exogenous TRB3 protein (Flag) was present in the M2TRB3 cells. No expression was noted in the protein samples derived from M2, M2mock, HEK293 and HepG2 cells (Fig. 1B). The M2TRB3 and M2mock cells were used for cell proliferation assays.

TRB3 gene enhances cell proliferation and tumor volume. To examine the tumorigenic activity of the TRB3 gene, we investigated its effects on cell and tumor growth using M2TRB3 and M2mock cells. The number of M2TRB3 cells significantly increased compared to M2mock cells at the 48 and $72 \mathrm{~h}$ time points $(\mathrm{P}<0.01$ and 0.05 , respectively) (Fig. $2 \mathrm{~A})$. At $72 \mathrm{~h}$, a 34\% increase was noted in the number of M2TRB3 cells compared to that of the M2mock cells. To examine the extent of M2TRB3 cell growth when these cells were implanted into the subcutaneous tissue of mice, we used the xenograft mouse model as described in Materials and methods. Twice a week observation was carried out with all mice throughout the experiment. Tumor growth was monitored with the naked eye from day 7 to 35 after inoculation; tumor volume $\left(\mathrm{mm}^{3}\right)$ and body weight $(\mathrm{g})$ were measured twice weekly. No specific physical and behavioral changes were noted in any mice. The average volume of the tumors derived from the M2TRB3 cells was significantly increased by $38 \%$ when compared with that of the M2mock tumors at experimental day $35(\mathrm{P}<0.05)$ (Fig. 2B). 

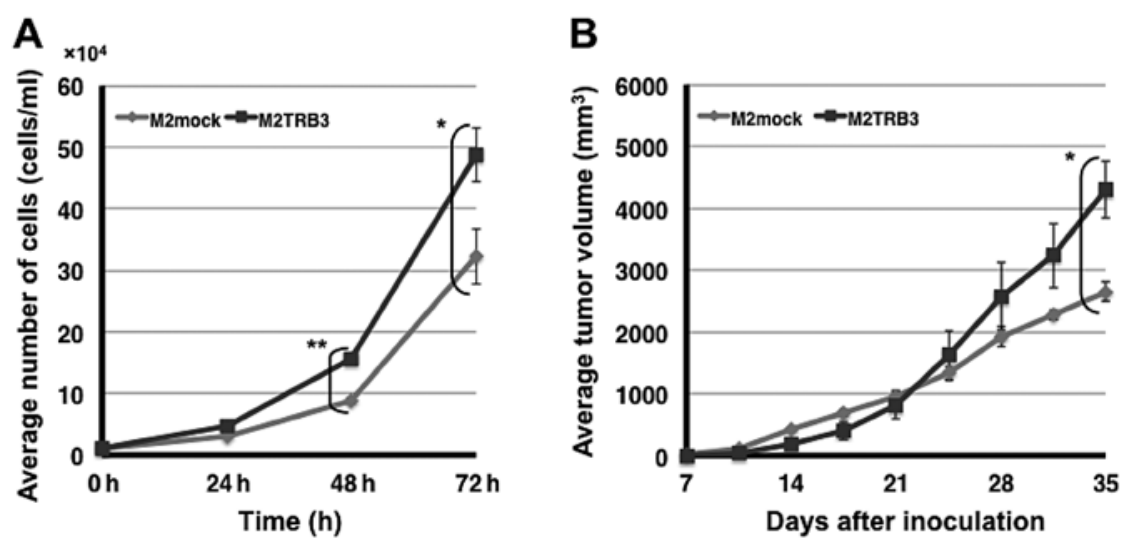

Figure 2. Growth enhancing effects of the TRB3 gene. (A) Growth curve of the cell proliferation assay. Asterisk(s) indicate statistical significance between the two cell lines $\left({ }^{*} \mathrm{P}<0.05,{ }^{* *} \mathrm{P}<0.01\right)$. (B) Volume of the M2TRB3 tumors and M2mock tumors. Asterisk indicates statistical significance in tumor volume between the two tumors $(" \mathrm{P}<0.05)$.
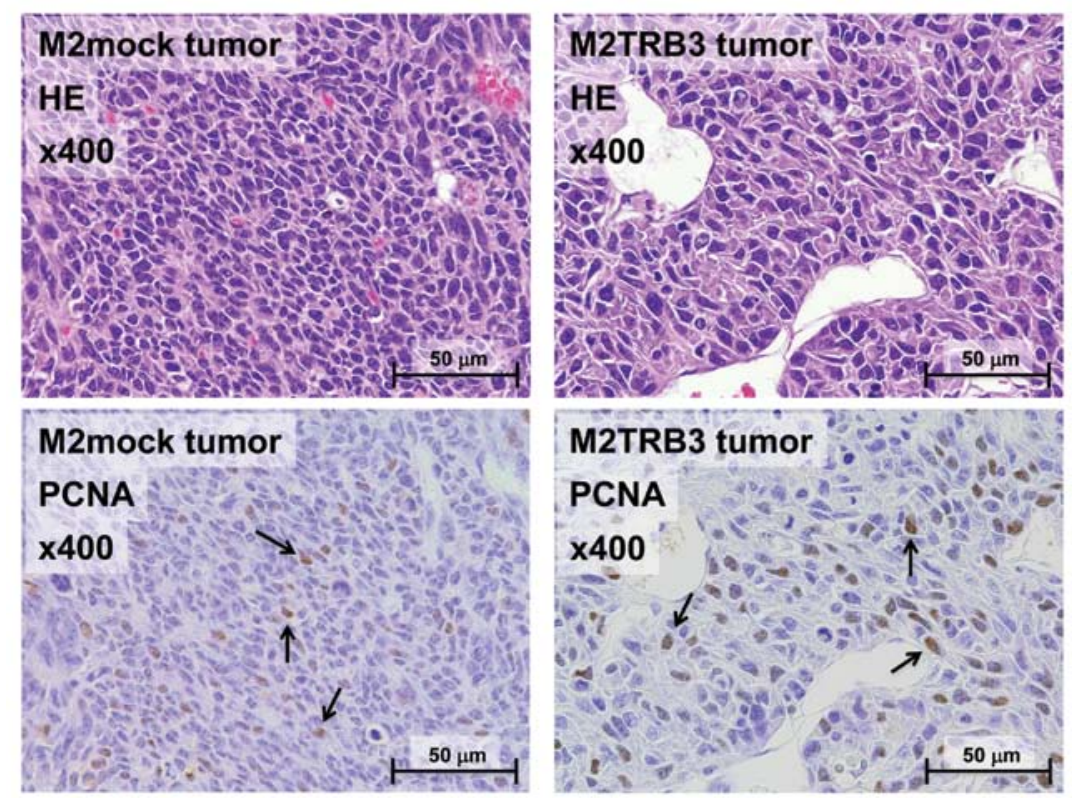

Figure 3. Representative histological features of the M2mock (left rows) and M2TRB3 tumors (right rows). Upper panels were stained with hematoxylin and eosin (HE) and lower panels show immunohistochemical staining of proliferating cell nuclear antigen (PCNA). Approximately 20 and $35 \%$ of M2mock and M2TRB3 cells were PCNA-positive (arrows), respectively. Magnification was x400 in all four images.

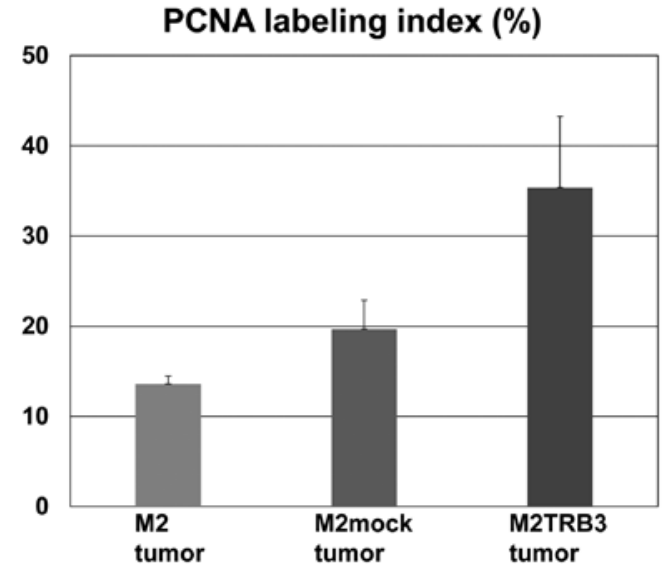

Figure 4. PCNA labeling index in the M2, M2mock and M2TRB tumors. A marked difference was noted between M2mock and M2TRB3 tumors but this difference did not achieve statistical significance.
Gross and histological features and PCNA labeling index of the M2TRB3 tumors. Due to the growth enhancing effects identified above, we aimed to determine whether the TRB3 gene induced morphological changes in tumor tissues. The M2TRB3, M2mock and M2 tumors were excised from the mouse skin, fixed with $10 \%$ buffered formalin, and stained with hematoxylin and eosin for histological examination. The tumors were analyzed using a light microscope. M2TRB3 and M2mock tumors presented a pedunculated round shape. Histologically, M2mock tumor cells grew in a solid appearance (Fig. 3, left upper panel). A site of necrosis was present in the central region of the tumor. M2TRB3 tumors were also solid and papillary growth was partially noted (Fig. 3, right upper panel). In the M2TRB3 tumors, the mean diameter of the nucleus $(9.4 \pm 0.3 \mu \mathrm{m})$ was significantly greater than that $(7.0 \pm 0.2 \mu \mathrm{m})$ of the M2mock tumors $(\mathrm{P}<0.001)$. The cell proliferation rate was evaluated by measuring the PCNA 
A

$\mathbf{O h}$

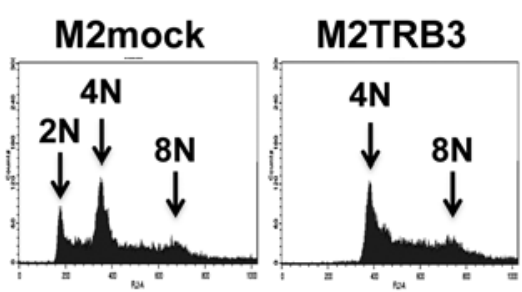

$72 \mathrm{~h}$

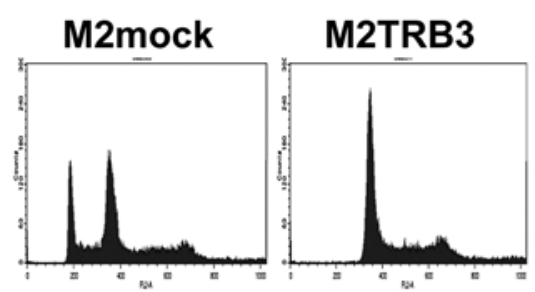

B

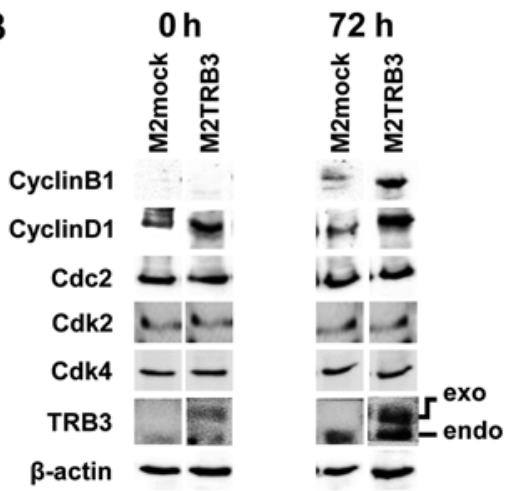

Figure 5. Effects of the TRB3 gene on DNA ploidy and protein expression. (A) Representative results of the flow cytometric analysis. After synchronizing cells in the G0/G1 phase, ploidy status was determined by flow cytometric analysis at 0 (left two panels) and $72 \mathrm{~h}$ (right two panels) in the M2mock and M2TRB3 cell lines. Note three peaks (2N, diploid; 4N, tetraploid; $8 \mathrm{~N}$, octaploid) in different locations in the DNA histogram. (B) Protein expression status of cell cycle control molecules and TRB3 in M2mock and M2TRB3 cell lines. Cell lysates were extracted at the indicated times (h) of the cell culture and then examined by western blot analysis for the indicated proteins, using the respective antibodies, as described in Materials and methods. $\beta$-actin was used as an internal control. Exogenous human TRB3 and endogenous mouse TRB3 are describes as exo and endo, respectively.

Table I. Distribution and rate (\%) of ploidy in the M2TRB3 and M2mock cell lines.

\begin{tabular}{lccc}
\hline & & \multicolumn{2}{c}{ Time (h) after starvation } \\
\cline { 3 - 4 } Cell line & Ploidy & $0 \mathrm{~h}$ & $72 \mathrm{~h}$ \\
\hline M2mock & $2 \mathrm{~N}$ & $12.1 \pm 0.3^{\mathrm{a}}$ & $16.6 \pm 0.1^{\mathrm{b}}$ \\
M2TRB3 & $2 \mathrm{~N}$ & $0.0 \pm 0.0$ & $0.0 \pm 0.0$ \\
M2mock & $4 \mathrm{~N}$ & $37.0 \pm 0.1$ & $38.5 \pm 0.2^{\mathrm{b}}$ \\
M2TRB3 & $4 \mathrm{~N}$ & $41.6 \pm 2.5$ & $57.5 \pm 0.5$ \\
M2mock & $8 \mathrm{~N}$ & $6.0 \pm 0.1^{\mathrm{a}}$ & $3.5 \pm 0.0^{\mathrm{b}}$ \\
M2TRB3 & $8 \mathrm{~N}$ & $25.3 \pm 1.8$ & $16.2 \pm 0.3$ \\
\hline
\end{tabular}

Differences in the percentage of ploidy in M2TRB3 and M2mock cell lines. M2TRB3 vs. M2mock, ${ }^{\mathrm{P}} \mathrm{P}<0.01$ and ${ }^{\mathrm{b}} \mathrm{P}<0.001$.

labeling index as described in Materials and methods. The PCNA labeling index of the M2TRB3 tumors was higher than that of the M2 and M2mock tumors but this difference was not statistically significant (Fig. 3 lower panels and Fig. 4).

TRB3 affects the ploidy distribution of mouse mammary tumor cells. Due to the differences in tumor morphology noted in Fig. 3, we examined the effects of the TRB3 gene on DNA ploidy in M2mock and M2TRB3 cells. After synchronizing cells in the G0/G1 phase, we conducted experiments at 0 and $72 \mathrm{~h}$ using flow cytometric analysis. Representative DNA histograms of the analysis for these cells are shown in Fig. 5A, and distribution and rate of DNA ploidy are shown in Table I. In M2mock cells, the average percentage of diploid nuclei measured $12-16 \%$. In contrast, no diploid nuclei were observed in M2TRB3 cells (Table I and Fig. 5A, far right panels). M2TRB3 cells showed a significant increase by 19 and $12 \%$ in the population of octaploid nuclei at 0 and $72 \mathrm{~h}$, respectively, when compared to $\mathrm{M} 2$ mock cells (Table I). There was also an increase (4-19\%) in the population of tetraploid nuclei in the M2TRB3 cells. These results indicate that TRB3 affects the status of DNA ploidy in mouse mammary tumor cells. M2mock cells exhibited population peaks of aneuploid nuclei $(2 \mathrm{~N}, 4 \mathrm{~N}$ and $8 \mathrm{~N})$, indicating that these cells harbor a variable number of chromosomes.

Expression status of TRB3 and cell cycle control molecules in M2TRB3 and M2mock cells. Due to the growth enhancing effects of TRB3 as noted in Fig. 2 and nuclear hyperploidy in M2TRB3 cells, we examined whether these cells affected the levels of expression of TRB3 and cell cycle control molecules. Thus, we measured the protein expression levels of TRB3 and cell cycle control molecules cyclin B1, cyclin D1, Cdc2, Cdk2 and Cdk4. In M2TRB3 cells, both exogenous and endogenous TRB3 were highly expressed at $72 \mathrm{~h}$ compared to M2mock cells that only expressed endogenous TRB3 (Fig. 5B, right two columns). In contrast, a weak expression level of endogenous TRB3 was observed at $0 \mathrm{~h}$ in the M2mock cells, and marginal expression was noted in both exogenous and endogenous TRB3 at the same time point in these cells. Cyclin B1 and cyclin D1 expression levels in the M2TRB3 cells increased at $72 \mathrm{~h}$ of the cell culture, in which tumor cells were out of synchrony, compared to those of the M2mock cells (Fig. 5B). Expression levels of $\mathrm{Cdc} 2, \mathrm{Cdk} 2$, and $\mathrm{Cdk} 4$ showed no change between the M2TRB3 and M2mock cells.

\section{Discussion}

Several human tumor tissues have recently been shown to highly express TRB3 mRNA (14). It has also been demonstrated by us that TRB3 regulates the stability of Cdc25A, an essential activator of CDKs (10). However, the precise role and functional morphology of TRB3 have not been established yet. Thus, we carried out the present study to provide further evidence concerning cell growth and morphological changes in mouse mammary tumor cells by focusing on the expression levels of TRB3 and cell cycle control molecules, cellular nucleus size, and the status of DNA ploidy. M2TRB3 cells showed a significant numerical increase compared to the control M2mock cells. As a result, the doubling time of the M2TRB3 and M2mock cell lines was approximately 12 
and $15 \mathrm{~h}$, respectively (Fig. 2A). A similar condition was also observed in the tumors, clearly indicating that in this context TRB3 had an enhancing property on the growth of mouse mammary tumor cells.

It is well understood that cell volume increases with DNA ploidy, and this correlation has been observed in a wide variety of eukaryotic cells (19). Increased DNA ploidy can exert its effects by increasing nuclear size, chromatin content, and the expression levels of a certain gene (19). We found that in the M2TRB3 tumors the mean diameter of the nucleus measured $9.4 \pm 0.3 \mu \mathrm{m}$ and that of the M2mock tumors was $7.0 \pm 0.2 \mu \mathrm{m}$. From the flow cytometric analysis we also found a significant increase in the population of M2TRB3 cells bearing tetraploid or octaploid nuclei compared to that of the M2mock cells bearing mostly diploid or tetraploid nuclei (Fig. 5A). These findings are consistent with those reported by Danielsen et al (20) who demonstrated that nuclei of 6.0-7.5 $\mu \mathrm{m}$ in diameter are classified as diploid, 7.5-9.0 $\mu \mathrm{m}$ as tetraploid, and 9.5-11.0 $\mu \mathrm{m}$ as octaploid. Collectively, TRB3 may have the ability of polyploidization during development.

Cyclins are the key molecules in cell cycle control due to their specific and periodic expression during cell cycle progression. Cyclin D1 complexes with Cdk4 and Cdk6 and thereby regulates transition from the $\mathrm{G} 1$ phase into the $\mathrm{S}$ phase by phosphorylation and inactivation of pRB (21-24). Phosphorylation causes release of the transcription factor E2F that promotes mitosis $(24,25)$. Gene amplification and/or protein overexpression of cyclin D1 occurs in a variety of human carcinomas and tumors in animal models $(26,27)$. Unlike cyclin D1, the activity of cyclin B1 is essential for G2/M phase of the cell cycle through a complex with Cdc2 (28). However, little is known about the association between DNA ploidy and cyclin B1/cyclin D1 expression status. We found elevated expression levels of cyclin B1 and cyclin D1 in M2TRB3 cells without significant changes in expression levels of $\mathrm{Cdc} 2, \mathrm{Cdk} 2$ and Cdk4 (Fig. 5B). Furthermore, M2TRB3 cells totally lack diploid nuclei but a population of the M2mock cells consisted mainly of diploid or tetraploid nuclei, suggesting that expression of cyclin B1 and cyclin D1 may positively correlate with the generation of hyperploid nuclei and thereby further promote the chromosomal instability in TRB3-overexpressing cells. Similar results regarding cyclin B1/D1 overexpression and promotion of tetraploidy or aneuploidy $(>2 \mathrm{~N})$ were previously obtained in human breast carcinoma and mouse myeloid cells $(28,29)$. As we found in the present study, the novel aspect of the TRB3 gene is that this gene induces an increase in cell proliferation and polyploidy leading to enlargement of the nuclear size of the implanted mouse mammary tumor cells. These effects of TRB3 may cause chromosomal instability. The detailed mechanism of this chromosomal instability is not known but may be related to the above-described effects of TRB3 on morphological function. In a recent study, we demonstrated that TRB3 may regulate the activity of anaphasepromoting complex/cyclosome (APC/ $\left.\mathrm{C}^{\mathrm{Cdh} 1}\right)$ that is a major ubiquitin ligase complex regulating the progression of the cell cycle through the ubiquitination and subsequent degradation of cell cycle control molecules including cyclin B1 $(30,31)$. In the present study, we found an elevated expression level of the cyclin B1 protein in M2TRB3 cells that overexpressed the human TRB3 gene. We should emphasize that two cell lines M2TRB3 and M2mock differ in synchrony status that may influence their response to morphological function. This intriguing respect may also reflect the role of cell cycle progression of TRB3. Thus, it is of interest to examine whether the TRB3 gene causes de novo morphological changes leading to tumorigenesis in a specific organ site. An additional study using the TRB3 transgenic animal model is currently in progress to answer this question.

\section{Acknowledgements}

We thank Dr Hiroyuki Tsuda for the valuable comments and discussions. We also acknowledge the excellent technical assistance of Kenta Moriwaki and Shuhei Ikenaga. This study was supported by a Grant-in-Aid from the Ministry of Education, Culture, Sports, Science, and Technology, and the Ministry of Health, Labour, and Welfare of Japan.

\section{References}

1. Grosshans $\mathbf{J}$ and Wieschaus E: A genetic link between morphogenesis and cell division during formation of the ventral furrow in Drosophila. Cell 101: 523-531, 2000.

2. Mata J, Curado S, Ephrussi A and Rørth P: Tribbles coordinates mitosis and morphogenesis in Drosophila by regulating string/CDC25 proteolysis. Cell 101: 511-522, 2000.

3. Seher TC and Leptin M: Tribbles, a cell-cycle brake that coordinates proliferation and morphogenesis during Drosophila gastrulation. Curr Biol 10: 623-629, 2000.

4. Bowers AJ, Scully S and Boylan JF: SKIP3, a novel Drosophila tribbles ortholog, is overexpressed in human tumors and is regulated by hypoxia. Oncogene 22: 2823-2835, 2003.

5. Bezy O, Vernochet C, Gesta S, Farmer SR and Kahn CR: TRB3 blocks adipocyte differentiation through the inhibition of C/EBP $\beta$ transcriptional activity. Mol Cell Biol 27: 6818-6831, 2007.

6. Chan MC, Nguyen PH, Davis BN, Ohoka N, Hayashi H, Du K, Lagna $\mathrm{G}$ and Hata $\mathrm{A}$ : A novel regulatory mechanism of the bone morphogenetic protein (BMP) signaling pathway involving the carboxyl-terminal tail domain of BMP type II receptor. Mol Cell Biol 27: 5776-5789, 2007.

7. Du K, Herzig S, Kulkarni RN and Montminy M: TRB3: a tribbles homolog that inhibits Akt/PKB activation by insulin in liver. Science 300: 1574-1577, 2003.

8. Qi L, Heredia JE, Altarejos JY, Screaton R, Goebel N, Niessen S, Macleod IX, Liew CW, Kulkarni RN, Bain J, Newgard C, Nelson M, Evans RM, Yates J and Montminy M: TRB3 links the E3 ubiquitin ligase COP1 to lipid metabolism. Science 312: 1763-1766, 2006

9. Tang M, Zhong M, Shang Y, Lin H, Deng J, Jiang H, Lu H, Zhang Y and Zhang W: Differential regulation of collagen types I and III expression in cardiac fibroblasts by AGEs through TRB3/MAPK signaling pathway. Cell Mol Life Sci 65: 2924-2932, 2008.

10. Ohoka N, Yoshii S, Hattori T, Onozaki K and Hayashi H: TRB3, a novel ER stress-inducible gene, is induced via ATF4-CHOP pathway and is involved in cell death. EMBO J 24: 1243-1255, 2005.

11. Sakai S, Ohoka N, Onozaki K, Kitagawa M, Nakanishi M and Hayashi H: Dual mode of regulation of cell division cycle $25 \mathrm{~A}$ protein by TRB3. Biol Pharm Bull 33: 1112-1116, 2010.

12. Jin G, Yamazaki Y, Takuwa M, Takahara T, Kaneko K, Kuwata T, Miyata S and Nakamura T: Trib1 and Evil cooperate with Hoxa and Meis1 in myeloid leukemogenesis. Blood 109: 3998-4005, 2007.

13. Keeshan K, He Y, Wouters BJ, Shestova O, Xu L, Sai H, Rodriguez CG, Maillard I, Tobias JW, Valk P, Carroll M, Aster JC, Delwel R and Pear WS: Tribbles homolog 2 inactivates $\mathrm{C} / \mathrm{EBP} \alpha$ and causes acute myelogenous leukemia. Cancer Cell 10: 401-411, 2006.

14. Xu J, Lv S, Qin Y, Shu F, Xu Y, Chen J, Xu BE, Sun X and Wu J: TRB3 interacts with CtIP and is overexpressed in certain cancers. Biochim Biophys Acta 1770: 273-278, 2007. 
15. Suzui M, Sunagawa N, Chiba I, Moriwaki H and Yoshimi N Acyclic retinoid, a novel synthetic retinoid, induces growth inhibition, apoptosis, and changes in mRNA expression of cell cycle- and differentiation-related molecules in human colon carcinoma cells. Int J Oncol 28: 1193-1199, 2006.

16. Suzui M, Inamine M, Kaneshiro T, Morioka T, Yoshimi N, Suzuki R, Kohno H and Tanaka T: Indole-3-carbinol inhibits the growth of human colon carcinoma cells but enhances the tumor multiplicity and volume of azoxymethane-induced rat colon carcinogenesis. Int J Oncol 27: 1391-1399, 2005.

17. Suzui M, Masuda M, Lim JT, Albanese C, Pestell RG and Weinstein IB: Growth inhibition of human hepatoma cells by acyclic retinoid is associated with induction of p21(CIP1) and inhibition of expression of cyclin D1. Cancer Res 62: 3997-4006, 2002.

18. Futakuchi M, Nannuru KC, Varney ML, Sadanandam A, Nakao K, Asai K, Shirai T, Sato SY and Singh RK: Transforming growth factor-beta signaling at the tumor-bone interface promotes mammary tumor growth and osteoclast activation. Cancer Sci 100: 71-81, 2009.

19. Jorgensen $P$ and Tyers $M$ : How cells coordinate growth and division. Curr Biol 14: 1014-1027, 2004.

20. Danielsen H, Lindmo T and Reith A: A method for determining ploidy distributions in liver tissue by stereological analysis of nuclear size calibrated by flow cytometric DNA analysis. Cytometry 7: 475-480, 1986.

21. Hunter T and Pines J: Cyclins and cancer. II: cyclin D and CDK inhibitors come of age. Cell 79: 573-582, 1994

22. Weinberg RA: The retinoblastoma protein and cell cycle control. Cell 81: 323-330, 1995.

23. Chellappan SP, Hiebert S, Mudryj M, Horowitz JM and Nevins JR: The E2F transcription factor is a cellular target for the RB protein. Cell 65: 1053-1061, 1991.
24. Wilson CS, Butch AW, Lai R, Medeiros LJ, Sawyer JR, Barlogie B, McCourty A, Kelly K and Brynes RK: Cyclin D1 and E2F-1 immunoreactivity in bone marrow biopsy specimens of multiple myeloma: relationship to proliferative activity, cytogenetic abnormalities and DNA ploidy. Br J Haematol 112: 776-782, 2001

25. Johnson DG, Schwarz JK, Cress WD and Nevins JR: Expression of transcription factor E2F1 induces quiescent cells to enter S phase. Nature 365: 349-352, 1993.

26. Staibano S, Lo Muzio L, Pannone G, Mezza E, Argenziano G, Vetrani A, Lucariello A, Franco R, Errico ME and De Rosa G: DNA ploidy and cyclin D1 expression in basal cell carcinoma of the head and neck. Am J Clin Pathol 115: 805-813, 2001.

27. Bartkova J, Lukas J, Strauss M and Bartek J: Cyclin D1 oncoprotein aberrantly accumulates in malignancies of diverse histogenesis. Oncogene 10: 775-778, 1995.

28. Collecchi P, Santoni T, Gnesi E, Giuseppe Naccarato A, Passoni A, Rocchetta M, Danesi R and Bevilacqua G: Cyclins of phases G1, S and G2/M are overexpressed in aneuploid mammary carcinomas. Cytometry 42: 254-260, 2000.

29. Yin XY, Grove L, Datta NS, Katula K, Long MW and Prochownik EV: Inverse regulation of cyclin B1 by c-Myc and p53 and induction of tetraploidy by cyclin B1 overexpression. Cancer Res 61: 6487-6493, 2001.

30. Ohoka N, Sakai S, Onozaki K, Nakanishi M and Hayashi H: Anaphase-promoting complex/cyclosome-cdh1 mediates the ubiquitination and degradation of TRB3. Biochem Biophys Res Commun 392: 289-294, 2010.

31. Lukas C, Sørensen CS, Kramer E, Santoni-Rugiu E, Lindeneg C, Peters JM, Bartek J and Lukas J: Accumulation of cyclin B1 requires $\mathrm{E} 2 \mathrm{~F}$ and cyclin-A-dependent rearrangement of the anaphase-promoting complex. Nature 401: 815-818, 1999. 